\title{
Segregación subjetiva en el ámbito local: el caso de la villa Francisco Coloane, Puente Alto, Santiago de Chile
}

Subjective segregation at the local scale: the case of the village Francisco Coloane, Puente Alto, Santiago de Chile

\author{
Historial del artículo \\ Recibido: \\ 14 de octubre de 2020 \\ Revisado \\ 03 de noviembre de 2020 \\ Aceptado: \\ 17 de noviembre de 2020
}

\section{Luis Armando Valadez Betancourt ${ }^{\mathrm{a}}$}

a Posgrado de Geografía, Universidad Nacional Autónoma de México, Ciudad de México, México. Correo electrónico: luisvaladez@comunidad.unam.mx

\section{Palabras clave}

Devoluciones espaciales, espacio local; estigmas territoriales, fronteras simbólicas, microxenofobia, segregación subjetiva.

\section{Keywords}

Local space, micro-xenophobia, spatial devolutions, subjective segregation, symbolic borders, territorial stigmas.

\section{Resumen}

El objetivo del artículo es profundizar en la segregación subjetiva, entendida como el conjunto de representaciones espaciales, la producción de fronteras simbólicas y en especial los procesos estigmatización territorial. Ello se lleva a cabo en una urbanización de vivienda social periférica de la ciudad de Santiago de Chile, en el actual contexto neoliberal, caracterizado por la mercantilización de los derechos sociales, entre estos, el derecho a la vivienda. El análisis de tipo cualitativo, basado en entrevistas a profundidad a dirigentes y funcionarios involucrados en el caso, nos permite rechazar la hipótesis "espacialista" sobre el origen de estas representaciones, -que suelen ser atribuidas al deterioro del hábitat- y proponer, en cambio, que son generadas en el marco de una estrategia que articula los intereses empresariales y el control político e ideológico. Sin embargo, las resistencias que emergen desde el territorio han logrado invertir esta lógica y buscan devolver la centralidad simbólica a la periferia precarizada.

\section{Abstract}

The objective of this article is to examine in depth the subjective segregation, understood as the set of spatial representations, the production of symbolic borders and especially the processes of territorial stigmatization that are presented in a peripheral social housing urbanization in Santiago de Chile, in the current neoliberal context, characterized by the mercantilization of social rights, among these, housing. The analysis, based on deep-interviews to leaderships and functionaries directed related with the case, allows us to reject the "spatialist" hypothesis about the origin of these representations - which are usually attributed to habitat deterioration - and to propose instead that they are generated within the framework of a strategy that articulates business interests with political and ideological control. However, the resistances that emerge from the territory have been able to invert this logic and try to return the symbolic centrality to the precarized periphery 


\section{Introducción}

La segregación urbana, entendida en su sentido más general como la homogeneidad socioespacial, la periferización (Da Cunha, Rezende-Alves \& Henriques-Ribeiro, 2020) y la dispersión urbana (Massey \& Denton, 1988, 1993), se exacerba en la sociedad capitalista globalizada; y al mismo tiempo, se pueden ofrecer resistencias, en forma de nuevas representaciones y prácticas que reinterpretan los estigmas territoriales, y generan nuevas centralidades. Una de las propuestas teórico-metodológicas que abordan lo urbano, y que mejor han sabido captar esta contradicción, es la de Lefebvre, quien sitúa al menos tres fases de esta tensión: en un primer momento, se pretende la hegemonía del espacio abstracto, que es el espacio de la mercancía, la acumulación y la planificación; es decir se impone "la tendencia a la homogeneidad y la eficaz aplicación del espíritu analítico, en y por la dispersión, la separación y la segregación" (Lefebvre, 2013, p. 344); al tiempo, surgen resistencias que se despliegan en el plano de la vida cotidiana y de las representaciones del espacio. Esta tensión puede generar un estallido, a partir de ciertas prácticas espaciales de apropiación que lo revolucionen, y que creen espacios diferenciales.

En un contexto de creciente financiarización de la economía, la construcción masiva de vivienda social ha producido mayor homogeneización del espacio y dispersión urbana, en detrimento de la integración y el fortalecimiento de subcentralidades. El espacio abstracto tiende a aumentar su capacidad de dominación, y los grados de libertad que ofrecen las prácticas reivindicadoras del espacio diferencial se reducen; las tres preguntas que guían este trabajo son: ¿cómo se produce la segregación subjetiva en una urbanización de vivienda social masiva y segregada? ¿qué resistencias se ofrecen a la segregación desde el ámbito local? ¿son estas resistencias relevantes en términos de la producción del espacio diferencial y de nuevas subcentralidades urbanas?

En la literatura especializada se mencionan una serie de factores objetivos y subjetivos que están directamente involucrados en la segregación en la escala local (figura 1). Por una parte, las condiciones de deterioro del hábitat (Boyack, 2017; Cruz \& Isunza, 2017; Mier y Terán, Vázquez \& Ziccardi, 2012; Naranjo, 2018; Pansza, Gutiérrez \& Ortíz, 2017; Salgado et al., 2017), así como los patrones de movilidad (Brevis \& Corvalán, 2019; Moreno, 2016; Nieuwenhuis, Tammaru, van Ham, Hedman \& Manley, 2019; Rokem \& Vaughan, 2018; Segura, 2012). Se ha indagado también en el papel que juegan las decisiones de localización residencial en la conformación de zonas urbanas segregadas (Carrillo, Pattillo, Hardy, \& AcevedoGarcia 2016; Kataure \& Walton-Roberts, 2015; Krysan \& Crowder, 2017; Krysan \& Farley, 2002; Sabatini, Rasse, Cáceres, Robles \& Trebilcock, 2017; Skobba \& Goetz, 2013; Teixeira, 2015; Theodos, Coulton \& Pitingolo, 2015; Villalobos \& Núñez, 2018; Villazor, 2017).

Por otro lado, las fronteras socioespaciales son de naturaleza simbólica, por lo que se ha indagado en los factores subjetivos que están implicados en la segregación urbana (Álvarez, 2017; Céspedes, 2019; Cornejo, 2015; Gómez \& Herrera, 2016; Hwang, 2016; Iglesias, 2014; Jarness, 2017; Moctezuma, 2017; Moreno, 2015; Oldrup, 2015; Roberti, 2013; Ruiz, 2016; Sabatini \& Rasse, 2017; Stevenson, Easterbrook, et al., 2018; Stevenson, McNamara, et al., 2018; Toft, 2018), y en especial, en los procesos de estigmatización territorial (Barahona \& Hinojosa, 2019; Bologna, Morales \& Plaza, 2017; Sabatini, 2015; Sabatini, Salcedo, Gómez, Silva \& Trebilcock, 2013; Santillán, 2017; Vázquez, Suarez \& Berríos, 2018).

Para Elorza (2019), la estigmatización territorial está vinculada a procesos de discriminación estructural que no pueden ser pensados fuera de la lógica de las clases sociales. Para Bayón (2012), el estigma territorial es ante todo discriminación de los pobres y de los lugares de los pobres. Para Sabatini et al. (2013), existen cuando menos dos diferencias entre los estigmas de los que hablaba Goffman y los estigmas territoriales, que forman parte de lo que el autor llama "conciencia de gueto"; mientras que en "la mayoría de los estigmas la cualidad estigmatizable es inseparable del individuo, en el caso del estigma territorial, esta es completamente disociable" (Sabatini et al., 2013, p. 48), lo que lleva implícito el hecho de que un individuo, al salir de un territorio estigmatizado, escapa de esta condición. Además, los estigmas territoriales estarían desplegados a distintas escalas geográficas.

En palabras de Goffman (1970), en el estigma se despliegan tanto la perspectiva normal, como la desacreditable: "el normal y el estigmatizado no son personas sino más bien, perspectivas" (p. 160). En el caso de los estigmas territoriales, para que el proceso se complete, es necesario que coincidan tanto factores externos, como la opinión de grupos sociales con poder sobre la desacreditación hacia los otros lugares, $\mathrm{y}$, asimismo, factores internos, como la vergüenza colectiva de habitar un territorio específico.

Para los autores, el estigma territorial es un "mecanismo de reproducción de las desigualdades sociales (...) que desempeña un papel relevante y de creciente importancia para la economía inmobiliaria, promoviendo la gentrificación" 


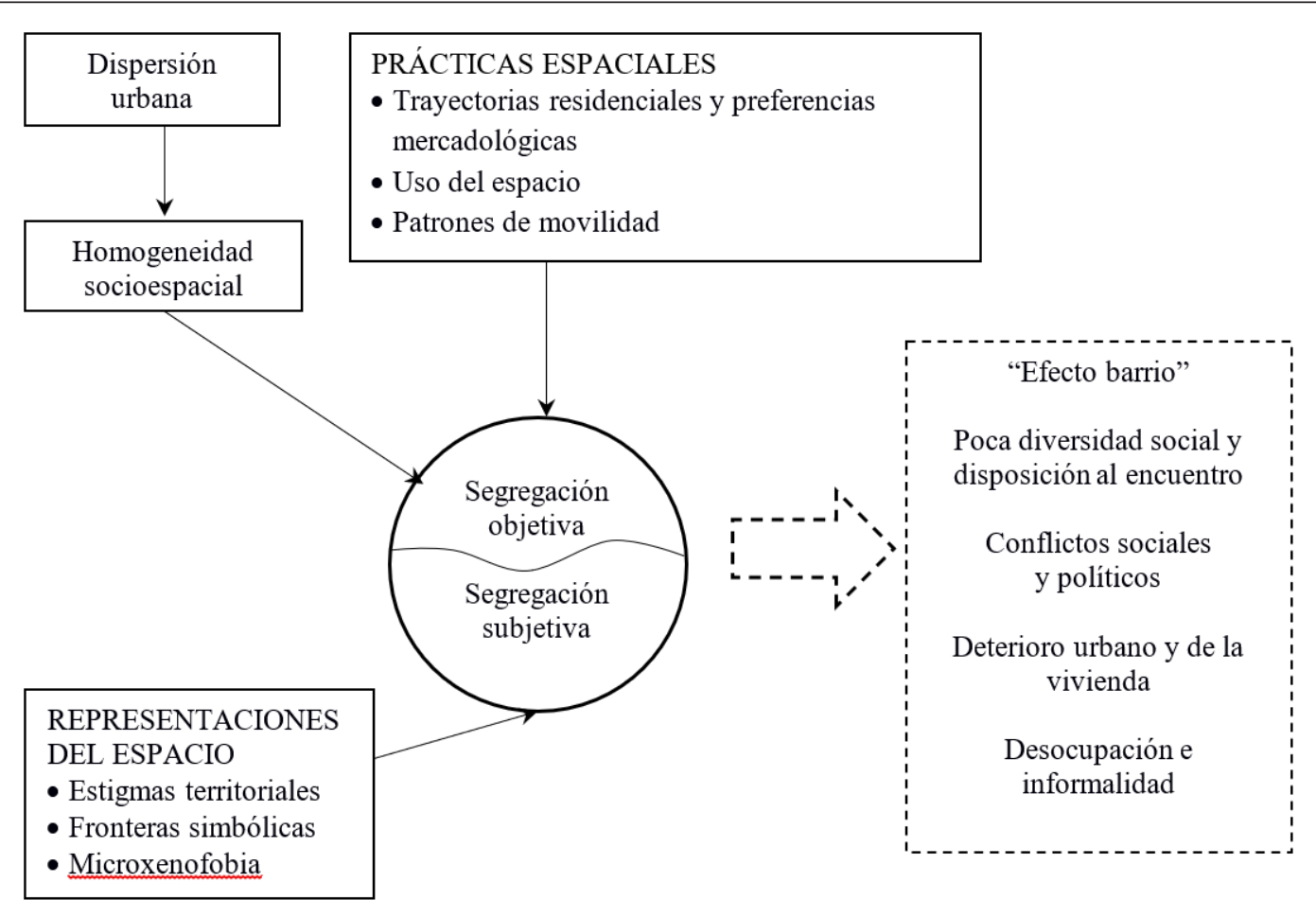

Figura 1. Procesos socioespaciales relacionados con la segregación residencial a escala local. Fuente: Elaboración propia.

(Sabatini et al., 2013, p. 49). Al mismo tiempo, recuperando a Tilly (2000), los autores consideran que el estigma territorial está motivado tanto por el acceso y control del territorio, como por la explotación de los habitantes estigmatizados.

Los estudios de caso sobre la estigmatización territorial revelan algunos aspectos importantes del proceso (figura 2). Por una parte, los mecanismos de estigmatización identificados han sido resistidos por la población que habita los lugares analizados. Es decir, que la respuesta a los estigmas territoriales es casi siempre de carácter colectivo, al contrario de los estigmas que se basan en "defectos" de los individuos. Así, una de las respuestas productivas frente a los estigmas ha sido el impulso de la organización popular para reducir la posibilidad de que el estigma sea aceptado por los pobladores (Sabatini et al., 2013).

\section{Materiales y métodos}

Entender las prácticas socioespaciales que se presentan en la escala local, y en particular las que tratan de romper con lo homogéneo, puede realizarse en clave lefebvriana, valiéndose de una perspectiva dialéctica y poniendo especial énfasis en la espacialidad e historicidad de los procesos urbanos. La metodología a la que recurrimos es de tipo cualitativa, mediante entrevistas a profundidad a un total de cinco dirigentas vecinales de la villa Francisco Coloane (figura 3) y funcionarios del Ministerio de Vivienda de Chile involucrados directamente en el caso, se utilizó la técnica de la entrevista semiestructurada, además de recuperar material hemerográfico y audiovisual. Se hace foco en tres de las representaciones del espacio relacionadas directamente con la segregación: los estigmas territoriales, las fronteras simbólicas y la microxenofobia.

\section{Antecedentes históricos de la comuna Puente Alto}

Durante la lucha por la independencia de Chile, la zona de Puente Alto es reconocida como un territorio fértil para la guerra de guerrillas, impulsada por el caudillo Manuel Rodríguez por su condición de paso. Una vez que triunfa el movimiento independentista, el sistema económico territorial implantado es el fundo (hacienda). En esta etapa, el llamado "Llano del Maipo" fue transformado por la construcción de canales de riego para las plantaciones de vid y su venta, conformándose una incipiente aristocracia terrateniente, descendiente de los encomenderos (Maffet, Molina \& Palma, 1948; Maureira, 2011; Valenzuela, 2010); el crecimiento demográfico de la ciudad de Santiago estimula en Puente Alto el arranchamiento y también 


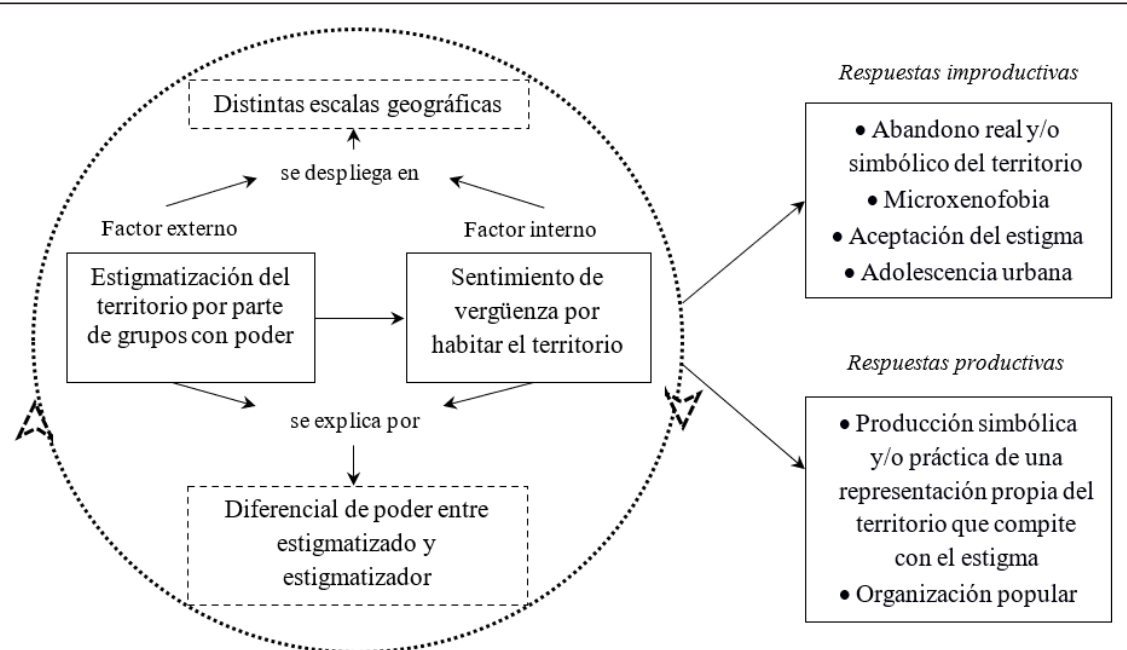

MECANISMODE REPRODUCCIÓNDE LA DESIGUALDAD

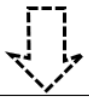

Economía inmobiliaria

Figura 2. Proceso de estigmatización territorial. Fuente: Elaboración propia.
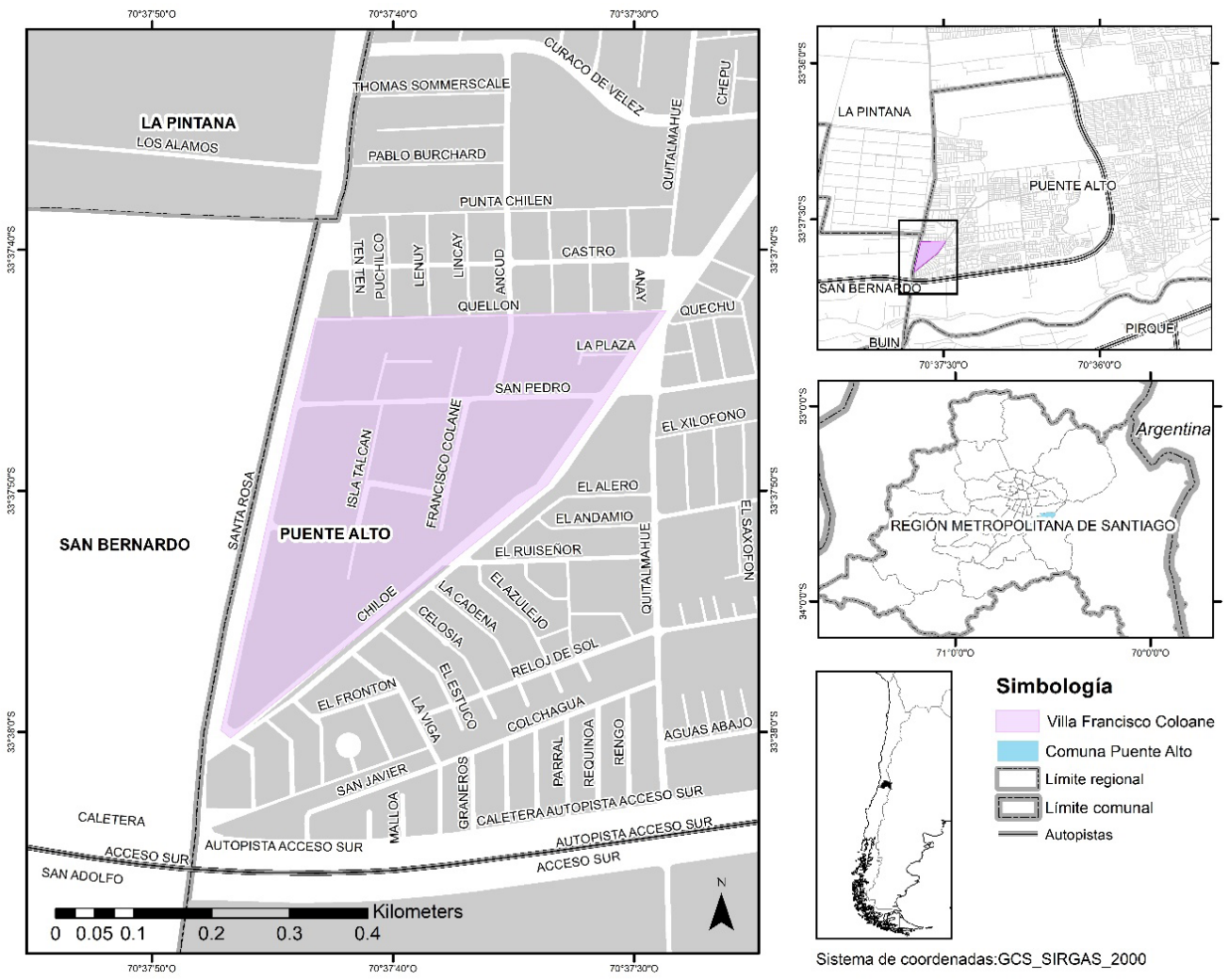

Figura 3. Localización de la villa Francisco Coloane. Fuente: Elaboración propia. 
se presenta el inquilinato; además, ocurre la primera ocupación suburbana formal de Santiago (Salazar, 1985).

Hacia el año de 1920, comienza un período de industrialización con connotaciones peculiares: algunos dueños de las industrias forman parte de la misma clase aristocrática que hereda de sus antepasados dueños de fundo la visión caritativa y paternalista hacia sus empleados, promoviendo la vivienda social, como una forma de conciliar sus intereses económicos de clase y una visión humanista cristiana (Miranda, 2017). La principal característica de la élite aristocrática chilena, ahora convertida en pequeña burguesía industrial, es su estrecha identificación con la élite gobernante, al punto que Salazar califica a esta clase como "empresariado estatal" (Salazar, 2003). En Puente Alto, son la familia de los Matte y los Alessandri -aristócratas de origen latifundista- quienes se posicionan en las altas esferas políticas chilenas. A partir de la instalación de fábricas, como la Compañía Manufacturera de Papeles y Cartones (CMPC), impulsan los primeros proyectos de vivienda social (Miranda, 2017).

La urbanización obrera surgida del paternalismo industrial tuvo, en Puente Alto, las siguientes características: a) se construyeron proyectos localizados cerca de las fábricas y del subcentro urbano; b) conformados por casas unifamiliares de tres piezas en lotes generosos de hasta 1,000 m2, esto les permitía a los habitantes mantener en sus viviendas actividades agrícolas de autoconsumo, complementarias al salario; c) el proyecto urbano incluía espacios públicos como plazas, escuela y para comercio y otros servicios; d) el financiamiento del proyecto corría a cargo de la empresa, mientras los obreros pagaban la vivienda a partir de descuentos directos al salario; e) mediante la vivienda obrera se busca - por parte del industrial- "moldear la vida familiar" de los empleados para incidir en la producción, moralizando la vida en la urbanización por ejemplo a través de las visitadoras sociales, pagadas por la empresa que se encargaban de conciliar en problemas intrafamiliares (Miranda, 2017).

Esto impactó en la subjetividad de los habitantes de origen campesino-obrero, y se presenta una situación compleja pues, aunque la vivienda es comprada y pagada rigurosamente, desde la perspectiva de los trabajadores, esta es ya una situación extraordinaria respecto de la mayoría de la deteriorada clase obrera santiaguina. Se auto perciben como privilegiados y avalan la figura del buen patrón con sensibilidad social, lo que apuntala al régimen aristocrático de la época (Miranda, 2017). En esta etapa, la comuna cuatriplica su población, pasando de 7,300 habitantes en 1930 a 30,400 en 1947. Hacia la década de los años 50, ya no son solo los industriales, sino que promotores inmobiliarios independientes, quienes impulsan la urbanización, mediante el loteo para su venta con facilidades (Maffet et al., 1948).

La hegemonía de la derecha aristocrática va a romperse provisionalmente con el triunfo de la Unidad Popular (1970-1973), formación política de izquierda liderada por Salvador Allende, que alcanza la presidencia e impulsa un programa socialista que incluía la estatización de algunas empresas, entre estas la CMPC que, al ser un monopolio de la industria del papel, es además un actor influyente en la prensa. El gobierno allendista procuró librarse del control económico y político del "viejo papelero", enfrentándose directamente con los Matte-Alessandri, a la vez que los obreros de la papelera se dividieron entre los adherentes a la UP, iy los obreros de derecha, que se sumaron a la campaña de "La papelera NO!" -intento reaccionario de la aristocracia para conservar sus privilegios, correspondido por una parte del sector obrero que tampoco quiere perder los suyos-. Unos días posteriores al golpe de Pinochet, los Matte-Alessandri se encargaron de asesinar a obreros allendistas usando un grupo de Carabineros de Chile (González, 2012).

Al contrario del urbanismo paternalista, impulsado en Puente Alto en la primera mitad del siglo pasado, hacia la década de los noventa, en el contexto del retorno a la democracia, se promueve en la comuna -y a nivel nacional- una política viviendista, que pone el acento en la cantidad de soluciones habitacionales, antes que en la habitabilidad. Hacia 1994, se publica el Plan Regulador Metropolitano de Santiago, incorporando paño urbanizable para el desarrollo de cuarenta y nueve villas. Se construyen un total de 25.466 departamentos, en blocks de tres niveles (Cociña, 2016; Gajardo Martínez, 2013). Por este cambio de uso de suelo, los terrenos resultaron baratos para las empresas desarrolladoras. Las primeras villas de Bajos de Mena, El Volcán I y II, fueron construidas por la empresa COPEVA, compuestas por edificios de tres pisos y viviendas con una superficie de $42 \mathrm{~m} 2$.

COPEVA fue una compañía inmobiliaria propiedad del empresario Francisco Pérez Yoma, hermano del encumbrado político del Partido Demócrata, Cristiano Edmundo Pérez Yoma. Cuando en 1997 el temporal de lluvias afectó los departamentos recién entregados a los vecinos de la villa El Volcán, pronto se da a conocer que habría sido construida de manera deficiente, con materiales de bajísima calidad y sin la fiscalización debida, a cambio de un soborno al más alto nivel del gobierno chileno. 
Incluso, el empresario le habría obsequiado un caballo pura sangre al entonces ministro de vivienda Edmundo Hermosilla, quien ante el escándalo se vio obligado a presentar su renuncia (Carvajal, 2012).

\section{El Programa "Segunda Oportunidad"}

Hacia el año 2012, el presidente Piñera anunció el Programa Recuperación de Condominios "Segunda Oportunidad" (en adelante PSO) como una estrategia para solventar "la mala calidad constructiva, hacinamiento y deterioro generalizado de bienes y espacios comunes que se transforman en focos de inseguridad; y problemas urbanos vinculados a su emplazamiento en sectores periféricos, sin adecuado acceso a fuentes laborales, servicios, equipamiento y áreas verdes" (MINVU, 2012, p. 23). Se seleccionó la villa Francisco Coloane y otros tres barrios de Chile para incorporarse al PSO (MINVU, 2016). El programa consistió en la expropiación voluntaria de la vivienda a cambio de un subsidio de 700 Unidades de Fomento (equivalente a 33,813.34 USD, tipo de cambio del 30 de agosto de 2013) para la adquisición de una nueva vivienda en otro lugar, caso contrario:

somete a los residentes a una expropiación, mediante la cual pueden recibir una compensación máxima igual a la tasación fiscal, que podría alcanzar aproximadamente 350 UF. Por su parte, la normativa del programa pone como condición para participar en él, y para aprobar la demolición de cada unidad habitacional o unidad mínima de postulación (UMP) — en general de 24 departamentos-, que al menos el 95 por ciento de los copropietarios estén de acuerdo, cifra que excepcionalmente podría llegar a una adhesión mínima del 85 por ciento. (Jiménez, 2015, p. 82).

El programa no tuvo la respuesta esperada, en cambio, se generó un conflicto vecinal de proporciones mayores, entre aquellos que estaban a favor de la demolición de sus departamentos y quienes se negaban a salir de la villa. De acuerdo a una de las entrevistadas, el PSO se impulsó mediante engaños a los vecinos, con el pretexto de gestionar mejoras en los departamentos:

Aquí hubo una maniobra política, muy estratégica y nosotros caímos, yo caí también. Ellos se tomaron del terremoto del 2010. Pasaron a los departamentos: 'ay, vecina, vecina, sabe qué, van a venir unos arreglos, nosotros vamos a postular para que nos vengan a arreglar'. Entonces yo caí po (...).por ejemplo, a una vecina se le caía el agua por la ducha, entonces había que sacarle fotos de que ahí esa ducha estaba mala, que había que venirla a arreglar (...) estos mismos tableros, que ya se partió por el terremoto, había que venir a cambiar el tablero, había que sacarle fotos (...) y firmamos para que vinieran a hacer los arreglos pertinentes, firmando el número de carnet, y toda la cosa, todo ese documento llega y lo presentó el Ossandón: que nosotros queríamos y que habíamos firmado para demolición. Jamás pues, por eso te digo, las cosas no son como las cuentan, nos engañaron... (Sra. Soledad, comunicación personal, 25 de abril de 2018).

Otra entrevistada relata que en la erradicación se cometieron atropellos por parte de las dirigentes que promovían el PSO:

Ahí empezó el hostigamiento por parte de estas señoras que venían a desalojar a la gente, a las que ellas querían les decían 'no, te vai y te vai' y te echan y te tiran todo pa afuera. Así era (...) uno les decía 'yo no me quiero ir'. Y ellas decían 'vos firmaste, te vai nomas, te vai nomas...' Traían unos cuantos matones, y sobre todo a la gente sola, entonces llegaban y se metían y sacaban las cosas, las tiraban, y decían 'ya, esta se va'. (Sra. María, comunicación personal, 25 de abril de 2018).

Una de las principales críticas al PSO es que el programa ha creado incertidumbre, porque no es claro sobre el destino de los terrenos (Mora, Sabatini, Fulgueiras \& Innocenti, 2014), lo que ha generado rumores entre los vecinos, sobre la posible gentrificación de la zona:

El Ossandón tiene a su papá socio de una constructora, una vez que (con el PSO) nosotros salíamos de aquí, el 'papito' compraba los terrenos, un 'coco mono', y construía aquí unos chalets de arriba de 60 millones. (Sra. Soledad, comunicación personal, 25 de abril).

Sea o no cierta la versión, en trabajos universitarios como el de Zomosa (2016) se propone un "cierre" del PSO en la villa, demoliendo los blocks que quedan. Este cierre consistiría en la "donación" de los terrenos expropiados a "una empresa o constructora", para la construcción de un "microcentro barrial con servicios y equipamiento" (figura 4). Más allá de la viabilidad técnica y social de tales proyectos, queda evidenciada la lógica hegemónica imperante del capital inmobiliario con respecto al desarrollo del sector: adquisición de terrenos baratos, subsidios focalizados y grandes ganancias, a costa de deudas, muchas veces impagables.

Pero también queda de manifiesto que la conectividad del sector no es un problema tan grave, como generalmente 

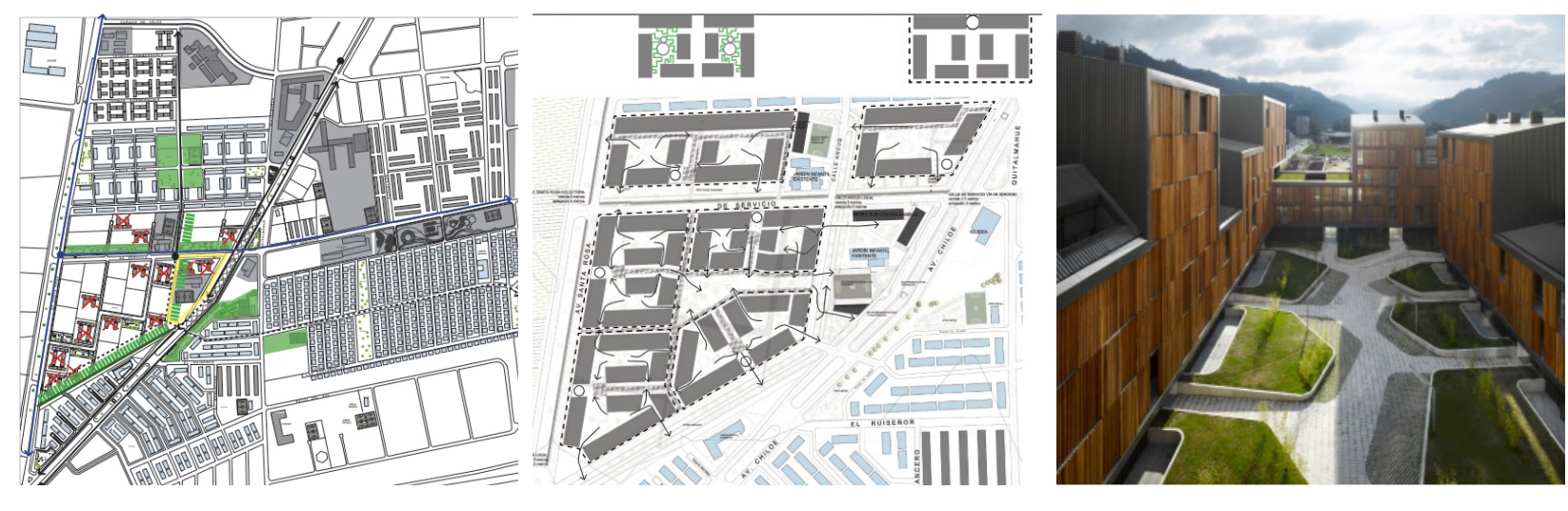

Nota: A la izquierda, plano de demolición de los blocks restantes; al centro, diseño urbano del "microbarrio"; a la derecha, modelo referencial para el proyecto (Zomosa, 2016).

Figura 4. Propuesta de Remodelación urbana en la villa Francisco Coloane. Fuente: Zomosa (2016).

se presume; lo mismo que la falta de equipamiento y servicios públicos. El mismo trabajo señala que:

En cuanto a los servicios y equipamientos cercanos (la villa Francisco Coloane) es uno de los sectores bien ubicados, ya que en un radio de 400 metros existen áreas verdes consolidadas como el Parque la Cañamera y Bajos de Mena, proyectos futuros como un skatepark y el centro cívico, y dos centros de salud primaria. En un radio de 200 metros se encuentran dos establecimientos educacionales privados y uno público y dos establecimientos de culto. Se concluye que existen servicios y equipamientos básicos, sin embargo, no hay establecimientos de recreación para los distintos grupos etarios ni comercios básicos como farmacias o supermercados. (Zomosa, 2016, p. 40).

\section{Resultados}

A continuación, se presentan los principales hallazgos divididos en dos partes: un apartado donde se muestran las principales representaciones del espacio, profundizando en el tema de la estigmatización territorial, y en un segundo apartado se profundiza en las fronteras simbólicas y la microxenofobia.

\section{Representaciones del espacio}

“Aquí está plagado de narcotraficantes, de gente que mete miedo, que amenaza, que, como dicen ellos, revientan departamentos. Nosotros tenemos que sacar a las personas de estos ghettos de pobreza (...) Tenemos que devolverle la dignidad a mucha gente" (Canal de Youtube, 2015).
Estas son las palabras con las que el alcalde de Puente Alto entre 2000 y 2012 y senador de 2014 a 2022, Manuel Ossandón, se refiere al sector Bajos de Mena, y en particular a la villa Francisco Coloane. El político surgido de la derecha chilena expresa lo que también ha sido una frase común en la prensa y la televisión para describir al sector: un "ghetto de pobreza y desesperanza". La gobernadora de la Provincia de Cordillera por su parte, lo calificó como "un ejemplo de las cosas malhechas, de lo que literalmente no podemos repetir" (Klein, 2013). Tales términos contrastan con la visión de algunos habitantes, quienes sostienen una narrativa casi bucólica para referirse a su barrio:

Hasta el 2003 nosotros vivimos una vida de sueño genial, en ese entonces terminó de estar don Sergio Roubillar, hasta el 2001 más o menos estuvo de alcalde, que nos ayudó bastante, nos ayudó porque nosotros pudimos conseguir una biblioteca, porque a nosotros nos quedaba lejísimos, aquí no había nada, absolutamente nada. Para allá había potreros, había chacras, era rico vivir aquí, porque teníamos la lechería, uno bajaba vendían choclos, hortalizas, íbamos a comprar a la misma mata, digamos, no teníamos feria... la leche a las seis de la tarde uno hacía cola (...) aquí era una cosa agradable, los vecinos, todos se saludaban, a pesar de que no nos conocíamos... (Sra. María, comunicación personal, 25 de abril de 2018).

Otra vecina coincide con esta descripción: “era súper lindo estar aquí, no teníamos locomoción mucha, era como rural, pasaba cada media hora, una hora, una micro para Santiago y nada más" (Sra. Soledad, comunicación personal). Llama la atención que en estas narrativas no se 
valora el alejamiento del bullicioso centro de Santiago como algo necesariamente malo, sino con aspectos positivos.

El estigma territorial es vivido en la villa Francisco Coloane como un problema concreto. Los testimonios hablan de la representación de su villa como "un asunto complicado":

aquí no comentan la realidad que es, porque siempre hablan otras cosas, yo le digo por ejemplo, aquí no dicen oooh hay gente que sí es trabajadora, hay muchachos que sí realmente estudian, son profesionales, eso no lo dicen solo dicen aaah los traficantes las mujeres, tal por cual, eso no lo dicen, entonces yo creo que eso para nosotros es complicado como dueños de casa ¿me entiende?, nosotros sabemos aquí que hay de todo...(Sra. María, comunicación personal, 25 de abril de 2018).

La situación vivida por las inundaciones, y las imágenes de las "casas de nylon" quedaron fijadas como referentes en la población, como parte del imaginario de la precariedad de la vivienda social chilena. Las "Casas de nylon", para referirse al sector, fue un apelativo que en los medios de comunicación se reprodujo a raudales, así como la frase "El ghetto más grande de Chile". Sin embargo, los hallazgos de la presente investigación nos muestran una fuerte resistencia al estigma por parte de los habitantes que actualmente residen en la villa, que se expresa claramente cuando una de las entrevistadas pide "evitar ser llamados 'ghettos"':

A mí me gustaría que ya no nos digan 'esto es un ghetto'. Que ya no nos digan ' $\because U y$, las mujeres andan moviendo la cartera!; todas son traficantes, todas son prostitutas, no hay hijos sanos. Nosotros queremos limpiar nuestro nombre. (Sra. Soledad, comunicación personal, 25 de abril de 2018).

Quizá pareciera exagerado el comentario de parte de la entrevistada, sin embargo, no es así; en efecto, la señora Pilar, una de las dirigentes vecinales de la villa Francisco Coloane, en entrevista para el popular periódico The Clinic, relató así la vida en su barrio: "Aquí hay harta lola de doce años deambulando en la noche haciendo sexo oral. He pillado a un montón. Lo hacen ahí mismo entre los medidores. Aquí pasan cosas y nadie hace nada" (Pizarro, 2013).

Otros vecinos también coinciden en criticar la estigmatización de la cual son objeto, pues la perciben originada desde el propio gobierno chileno (Jiménez, 2015). Nos preguntamos entonces ¿cuáles han sido los argumentos "objetivos” de la estigmatización? Uno de los defectos más recurrentes es el que tiene que ver con la situación de hacinamiento. La misma dirigente citada lo describe así, en una entrevista con el noticiero 24 Horas (2013): “(los departamentos) son espacios reducidos, con mucha cantidad de gente lo que hace que no hay intimidad, no hay una cosa muy propia de uno, yo creo que hasta la dignidad se pierde acá (...) Muchas madres han perdido a sus hijos a través de la droga. Se han suicidado. Los niños no pueden salir a jugar al patio...”.

Sin embargo, hay estudios en la zona que demuestran que en realidad el hacinamiento no es generalizado en el sector y solo involucra a una cuarta parte de los departamentos de la villa:

De acuerdo al estándar establecido por la Organización Mundial de Salud (OMS), se considera como mínimo $10 \mathrm{~m} 2$ de vivienda por persona. De acuerdo a la encuesta, un $73 \%$ de las viviendas (de la villa Francisco Coloane) cumplen con los requerimientos mínimos; sin embargo, en un $22 \%$ de las viviendas viven entre cinco a seis personas y un 5\% entre siete hasta doce personas por vivienda, teniendo como promedio cerca de $5 \mathrm{~m} 2$ por persona, la mitad del mínimo establecido. (Zomosa, 2016, p. 44).

Sobre este tema, una entrevistada señala que hablar de hacinamiento fue una estrategia mediática para llevar a cabo la erradicación, y que en este caso los vecinos involucrados "se aprovecharon de las circunstancias":

Mostraron todo lo peor. Mostraron a la Vilma, a la Vilma en la tele la mostraron. Claro, en ese tiempo su mamá estaba viva, ella cuidaba a su mamá. Pero la Vilma era dejada po. En todo. De hecho, uno habría puerta, y sentía el olor al pipí de la mamá po. (...) Entonces esa gente se aprovechó de esas circunstancias. (Sra. Soledad, comunicación personal, 25 de abril de 2018).

En la misma perspectiva, se señala esta estrategia de victimización para promover el PSO:

Venía la prensa, y ellas (las dirigentes pro-PSO) hacían cosas, po. Salieron por la tele llorando porque ' $i a y$, es que nuestros hijos!... nosotros queremos que puro demuelan, porque nuestros hijos están tan hacinados, y algunos ya se están intentando matar'. Si era el único hijo de ella que se había ahorcado, po, pero no era porque estaba hacinado, era otra la situación: el cabro había repetido como tres años, más encima, 
el cabro se drogaba, más encima también andaba metido en otros líos, más encima la polola lo dejó. Era un conjunto de cosas que tenía él para haber hecho eso, po. (Sra. María, comunicación personal, 25 de abril de 2018).

Esta percepción de la estigmatización como parte de una estrategia estatal en acuerdo con las "líderes" del sector para promover el PSO parece confirmarse cuando una de las dirigentes, la señora Viviana, adheridas al multicitado programa menciona que:

Por ejemplo, hoy día, el Huguito que vive allá al frente que tiene setenta y ocho años está en un tercer piso con diálisis, entonces, todos esos casos los empezamos a mostrar nosotros y dijimos: 'ya, peliemos por esto'; este block, donde yo estoy parada fue el primer block que se preparó para salir y salió el 15 de mayo de 2013. ¿sabis que yo nunca me voy a olvidar de ese día, ese día las chiquillas estaban contentas, se iban a su nuevo hogar (...). (Canal de Youtube, 2015).

La señora Pilar, otra dirigente vecinal de la villa, favorable al PSO, comenta lo siguiente en una entrevista para The Clinic:

Yo no permitiría jamás que alguien más viva en esta mierda y destruya su familia. He visto mujeres muertas por la desesperanza, jóvenes ahorcados que yo misma he tenido que descolgar y otros que se han quemado vivos en los postes por robar cables. Los cabros se están muriendo por la droga. Mis vecinas salen los domingos como burras llevándoles mercadería a sus hijos a las cárceles. El mundo exterior no conoce lo que pasa aquí. (Pizarro, 2013).

\section{Estigmatización territorial y organización vecinal}

Sabatini (2015) considera que una forma de superar la estigmatización territorial, y en particular aquellos aspectos que deterioran la identidad individual y colectiva de los habitantes, ha sido la organización vecinal. El autor señala que en un contexto de lucha por el espacio "ardua y sofisticada", la estigmatización puede ser contestada "desde la base social y potencialmente desde las políticas públicas" (p. 70); a estas acciones contrahegemónicas, que tienen como referencia el territorio, las llama "devoluciones espaciales". Así, ardua y sofisticada ha sido la resistencia a la estigmatización por parte de los pobladores que se niegan a dejar la villa. Uno de los hallazgos más importantes es que esta organización ha evolucionado hacia formas complejas de participación vecinal y de redes de apoyo, que les permiten llevar a cabo su resistencia; esta se lleva a cabo a veces, con acciones mínimas, como la limpieza colectiva los espacios públicos, y en otras ocasiones, realizando manifestaciones, eventos culturales o reuniones con distintas instancias gubernamentales y políticos importantes; es decir, actividades que demandan un mayor grado de organización y compromiso.

Una de las devoluciones espaciales más notables ha sido resistir al estigma reivindicando el nombre de "Francisco Coloane" para la villa. Para los vecinos involucrados, esto significa recuperar y visibilizar el orgullo de vivir en su propio espacio -el espacio singular, en términos de Lefebvre-, comenzando por valorar su toponimia:

Nosotros aquí, en vida, trajimos a Francisco Coloane. Un gran escritor que no fue reconocido aquí en Chile, sino que en el extranjero. Allá lo eligieron como el mejor escritor, y aquí en Chile ni lo pescaron. Porque ni siquiera cuando falleció, ni siquiera lo tomaron en cuenta. Nosotros sí, en ese entonces, fuimos a la Biblioteca Nacional, ahí lo velaron un par de horas, porque de ahí se lo llevaron a Chiloé. Nosotros tuvimos mucho contacto con la viuda, con su hijo Francisco. (...) Incluso le tenemos un pergamino grande de recordatorio para entregárselo (...) lo que nosotros queríamos que él como hijo no dejara que se dejara de llamar aquí Francisco Coloane. Lo que más nosotros pedimos que esta villa no deje de llamarse Francisco Coloane. (Señora Soledad, comunicación personal, 28 de abril de 2018).

Otra de las estrategias desplegadas por los pobladores que han decidido permanecer, para combatir el estigma, ha sido el proyecto de "Bajos de Mena TV". Pero quizá el producto más importante de la organización de los vecinos que decidieron resistir la erradicación es el lanzamiento del Plan Integral Bajos de Mena, gestionado en el Gobierno de Michelle Bachelet; las vecinas lo relatan así:

Empezamos con las autoridades que teníamos, digamos, como cómplices nuestros, como era el (senador Carlos) Montes. Y después yo era amiga con el Claudio Orrego que después fue intendente (...) Un día cuando vino (la presidenta al evento de) lo de la mujer, ahí en el 25 de Santa Rosa, (...) habían unos parlantes ¡inmensos! Y yo no podía pasar. Y cómo cresta, yo no sé... Me subí arriba de esos parlantes y me tiré por encima, para tirarle una carta nada más. Si ahí, como se llenan de guardias y todo... '- ¿Y tú?, pero por favor, ¡Pero si ya las conozco! -me dijo (la presidenta Bachelet), — ¡si ya están listas! 
Ya tienen el proyecto listo, las casas ya están, no te preocupes'. '-Es que nosotros necesitamos otra cosa -le contesté. Si ella hubiese decretado todo, ningún problema, pero nosotros estábamos al aire igual, po. Nosotros necesitábamos otro sistema. Entonces nos invitó, y en una reunión (la presidenta) nos dice "¿Saben qué? les voy a decretar un Plan Integral... (Sra. María, comunicación personal, 25 de abril de 2018).

El PI es visto como uno de los "logros" de la organización de quienes decidieron quedarse. Una de las entrevistadas observa que los espacios públicos en la villa han sido gestionados con base en la organización vecinal:

Se eligió una buena junta de vecinos que nos ayudó bastante, entonces así cooperamos, tanto los vecinos como la directiva de la junta de vecinos, entonces, nos juntamos varias personas, con distintas ideas, para algunas cosas que nos faltaban, los chiquillos, sanos en ese entonces, hicieron un club de fútbol, un centro cultural primero, en el cual ese centro cultural puso fútbol, trajo básquetbol, mucho deporte, y además también a nosotros nos enseñaron a bailar cueca, también había talleres de artesanías, talleres de todo tipo que se les traían para que la gente de pocos recursos pudiera ir más o menos ayudándose con lo que aprendiera, también se hizo un centro, un club de ayuda al minusválido Todo eso a través de la unión de los vecinos. (Sra. Soledad, comunicación personal, 24 de abril de 2018).

\section{Microxenofobia y fronteras simbólicas}

De las fronteras subjetivas más notables encontradas en los relatos, es aquella que se establece con "los tomadores", como se les llama a las personas que ocupan los departamentos deshabitados del sector, y con esta acción, además de subsanar su necesidad de techo, intentan visibilizar su situación de "sin casa", ante una eventual acción del gobierno. La situación de los “tomadores", es vista de la siguiente forma por la señora Pilar, dirigenta pro-PSO:

Muchos de los vecinos de aquí no pagan arriendo, no pagan agua, no pagan luz, por lo general los "tomadores" deben dos millones, tres millones, y los hacemos pagar 200 mil pesos... yo creo que, si este Programa de Segunda Oportunidad lo entorpecen esos frescos, sinvergüenzas, que no tienen ninguna dignidad, no merecen estar acá... (MINVU, 2013).
Los "tomadores" no son nuevos en la villa; la implementación del Plan de Movilidad, que incluyó la demolición de los departamentos afectados por las lluvias en 1997, atrajo desde entonces a una gran cantidad de personas "sin techo" a los departamentos desocupados (Cociña, 2016). Aún más, de los relatos y testimonios escritos y audiovisuales, se puede desprender que una gran parte de los "propietarios" de un departamento en la villa proviene de campamentos informales, es decir, que alguna vez fueron "tomadores".

La estigmatización que se hace de los "tomadores" se corresponde con la llamada "adolescencia urbana" (Sabatini et al., 2013). En su búsqueda de afirmar una presunta "identidad de clase media", estos pobladores no desean ser confundidos con aquellos de los que alguna vez fueron parte. Esta reacción es, como plantea Sabatini, una respuesta radical al estigma: crear una identidad distinta a la estigmatizada. Lo preocupante, señala el autor, es que las autoridades a cargo de los programas de vivienda social no tomen en cuenta la adolescencia urbana, o incluso la estimulen y terminen exacerbando los conflictos y la desunión.

El estigma sobre los "tomadores" ha sido alentado por las autoridades. Por ejemplo, en palabras del alcalde Germán Codima (proveniente del partido Renovación Nacional), ellos no pueden reclamar derechos, en tanto no son propietarios: "El que se tomó un departamento, es un ocupante ilegal; $y$ en eso tiene que entender, que nosotros como servicios públicos, no tenemos ninguna herramienta legal como para poder comprarle un departamento que no es de él" (MINVU, 2013).

Sin embargo, de acuerdo a testimonios de los entrevistados, los "tomadores" han sido también utilizados por las autoridades, como parte de la estrategia de desocupación, para mostrar las condiciones de deterioro y hacinamiento del sector, y así, justificar la erradicación, incluso, haciéndolos pasar por "propietarios":

(Llegó a la villa el ministro de Vivienda a un recorrido) a las siete de la mañana, allá al fondo, a donde hay puros tomadores (...) los hicieron pasar a ellos como dueños propietarios. ¡Que están hacinados! ¡que están viviendo así, en estas condiciones!, ¡mira como lo tienen y toda la cosa! ¡Mentira, si ellos son tomadores! ¿Por qué no nos vinieron a preguntar a la gente que está aquí, si nosotros somos los propietarios? Entonces por eso nosotros fuimos allá altiro a decirles (...) le explicaba a la jefa de gabinete el otro día: ¿cómo es posible que haya ido el ministro a hacer un recorrido a las siete de 
la mañana y no nos haya convocado a nosotros, a los propietarios? (Sra. Soledad, comunicación personal, 25 de abril de 2018).

Las expresiones de algunos vecinos dan cuenta de que el conflicto entre propietarios ha ido escalando, sin que hasta la fecha se brinde respuesta a una problemática que las mismas autoridades han generado: "Esto es una guerra desatada entre propietarios y tomadores, que al menos yo, la perdí" (Jiménez, 2017, p.57). Un dirigente de la villa El Volcán, recurriendo a la analogía bélica, explica la situación de los tomadores y porqué la dinámica que se genera a partir de las demoliciones no parece tener fin, en tanto haya personas en necesitadas de una vivienda:

Nosotros podemos decir que se ha formado un tema de guerra, de posicionarse de algo, por ejemplo: esta es la chimenea que está dando la solución, por lo tanto yo traigo al tío, al abuelo, al papá, al hermano, al gato, al perro, y le chanto un departamento, porque así es la temática (...) no hay una ordenanza ni del SERVIU, ni del MINVU, ni del ministerio, ni de nada, (...) ayer anduve en una reunión con el SEREMI y no tiene respuestas para esto. (Varela \& Suárez, 2014, p. 156).

En suma, hay una actitud de microxenofobia específicamente con el grupo de los tomadores, que son los ocupantes ilegales de departamentos desocupados por los programas de erradicación que desde 1997, que ocurrieron las afectaciones por el temporal, han venido jugando una dinámica espacial específica en la zona. Sin embargo, pocas investigaciones han profundizado en el perfil, las trayectorias y las necesidades de este grupo social, que permanece como una suerte de "subclase" sin voz, contribuyendo así a su re-estigmatización.

Es importante hacer una diferencia entre el fenómeno de la "toma de terrenos" o en este caso, de departamentos, del estereotipo del "tomador". Las tomas han sido en Chile, al igual que en otros países, estrategias legítimas de acceso al suelo y la vivienda de las clases populares en un contexto en el que estos bienes son un privilegio, inaccesible a la mayoría de la población. El estereotipo del "tomador", en cambio, es un constructo social específico, que da señales de cuáles serían los elementos valóricos que subyacen a la condición estructural de privación.

Así, la imagen del "tomador" -sumada al deterioro inducido de la villa, y la microxenofobia que se descarga sobre este grupo social- es similar al estereotipo del flaite, que, como se ha propuesto en otro estudio, funciona en términos de referente afianzador de la ética del trabajo, en términos de lo que plantea Bauman (Saieg \& Valadez, 2013). El estereotipo del "tomador" refuerza una "ética del propietario" en la "sociedad con casa", como llamaba Bourdieu (1997) a aquel orden en que la norma exige un afán de perpetuar la vivienda como conjunto de bienes que orienta la existencia material y simbólica.

\section{Discusión}

Podemos adelantar, a partir de los testimonios recabados y de la indagación en numerosos archivos digitales y audiovisuales disponibles, que la estigmatización del sector Bajos de Mena, y en específico de la villa Francisco Coloane corresponde a una estrategia deliberada impulsada desde el Estado chileno con el objetivo de mantener el esquema mercantilista de la vivienda social, y al mismo tiempo, dar una imagen pública de renovado interés en los problemas de los menos favorecidos.

Esta estrategia tiene como ejes discursivos: 1) la estigmatización territorial de la villa, y 2) un neopaternalismo que revictimiza a los habitantes al condicionarles los beneficios de la política social a un permanente acto perfomativo de autoflagelación simbólica, escenificado en los principales medios masivos de comunicación. Aunque la estrategia proviene del ala derecha de la clase política chilena, el relato ha sido transversalmente reproducido, independientemente de las coordenadas ideológicas o partidistas, lo cual ha generado en la villa un estado de indefensión difícil de superar.

Como afirma Goffman (1970), en la estigmatización, lo importante no es que el estigmatizado tenga los defectos que se le señalan, sino que él lo crea. La dinámica del estigma territorial no inicia a partir de los defectos de la villa, como consideran Zapata, Galleguillos \& Wehrhahn (2009), cuando mencionan que:

El paisaje barrial de Bajos de Mena es agravado por conductas delictuales, especialmente consumo y tráfico de drogas, de amplio conocimiento de la opinión pública nacional a través de los medios, $\mathrm{y}$ cuyo resultado es una profunda estigmatización de Bajos de Mena y sus habitantes. (p. 637).

El estigma territorial no es resultado de ciertas condiciones urbanas y "delictuales", sino que tiene una importancia mayor, como activador de ese deterioro. Como señala Goffman, es necesario que los signos del defecto puedan ser reconocidos. En este sentido, el estigma funciona en 
la medida en que la performance referida se lleve a cabo de manera convincente, por lo cual, y quizá de forma deliberada, el Estado no mejora las condiciones físicas de los conjuntos, para mantener esa imagen y facilitar la desocupación del territorio; esto se puede verificar cuando se multiplican los testimonios de un evidente abandono: la solución al estigma territorial es, según el Estado, salir de la villa. Sin embargo, es conveniente interrogarnos si el deterioro de la identidad de los habitantes -que se expresa en la vergüenza y la aceptación del estigma-, se presenta en la villa y en qué nivel (individual o colectivo).

En el caso de las dirigentes pro-PSO, que son quienes más recurren al discurso estigmatizador, es difícil definir si sus opiniones son honestas o espontáneas, ya que se realizan en un entorno controlado, ante las cámaras de televisión $\mathrm{y}$ periodistas que tienen una perspectiva interesada $-\mathrm{y}$ no "escolástica", en términos de Bourdieu (1997)-. De los discursos revisados no se infiere alguna sensación de vergüenza, en el sentido que plantea Sabatini et al. (2013); en cambio encontramos relatos que podríamos calificar como vergonzantes, por ejemplo, calificar a la villa como "una mierda".

Los defectos de la villa que más se señalan han sido puestos en duda por investigaciones de gabinete y de campo: el multicitado problema del "hacinamiento" se reduce solo a una cuarta parte de los departamentos. La delincuencia y el microtráfico no son más altas en Coloane que en otros sectores del municipio. Los departamentos no tenían fallas constructivas graves y habían resistido a un fuerte terremoto en el año 2010. De este modo, para realzar el estigma se recurre a la generalización, a las descripciones exageradas, las frases efectistas y altisonantes, los detalles grotescos de la vida cotidiana en la villa e incluso a la mentira y la manipulación de temas sensibles, como la vulnerabilidad de la infancia (por ejemplo, los "niños quemados" del discurso de Ossandón; los "niños suicidas" de las dirigentes pro-PSO), el consumo de drogas y el ejercicio de la sexualidad.

No está demás señalar que la corrupción inmobiliaria, en particular la que involucró a la empresa COPEVA en una trama de sobornos con los más altos representantes del Estado chileno, ha pasado a segundo plano. Inclusive en el ámbito de la investigación académica, en la mayor parte de investigaciones sobre el caso de la urbanización en Bajos de Mena no se menciona el asunto, y solo algunas pesquisas han resaltado lo que en los medios de comunicación masiva fue un escándalo más de la agitada política chilena. Esta es otra consecuencia de los procesos de estigmatización territorial: el mantenimiento del status quo, a partir de problematizar la vida cotidiana de los pobladores, y no la de quienes se han beneficiado con el modelo actual de ganancias exorbitantes, a partir de la-más que clara- convergencia del empresariado inmobiliario con la clase política. El ocultamiento deliberado de las causas principales del deterioro físico de las urbanizaciones, resaltando en cambio sus consecuencias como "patologías", se confirma cuando el principal implicado en el fraude de las casas COPEVA, en vez de ser sujetado a algún tipo de responsabilidad, es nombrado ministro del Interior en el Gobierno de la presidenta Michelle Bachelet (2008-2010).

Por otra parte, como resaltamos al inicio de los hallazgos, la estigmatización como performance político, pone en relieve las diferencias (jerarquías) en clave aristocrático-autoritaria. Esto es evidente en el discurso de Ossandón, cuando menciona que "ellos" (refiriéndose a los estigmatizados) comparecen ante un "nosotros" (representantes del poder, es decir el Estado); para que, por obra y gracia de sus políticas, que corrigen ciertos errores del pasado, les sea restituida la dignidad perdida.

Así, en sentido contrario a los postulados que reivindican a la vivienda como parte de los derechos humanos universales, las evidencias muestran una visión de la derecha chilena, donde la dignidad humana no está dada, sino que es establecida en el marco de la meritocracia y el paternalismo. Sería ingenuo creer que en el caso de la villa Francisco Coloane, la "indignidad" se refiera únicamente al deterioro del espacio físico, sino que se trata de una definición simbólica que trae tras de sí un conjunto valórico, identificado con los ejes axiológicos de la derecha chilena: meritocracia, cultura del esfuerzo, caridad cristiana y, ante todo, una exaltación de la mercantilización de las necesidades humanas y sociales. ¿Cómo entender que la expropiación de un patrimonio familiar, sin una justificación adecuada, con una retribución injusta -pues se ejerce mediante un "subsidio" definido unilateralmente-, sea presentada por las autoridades como una cuestión de "dignidad", y rematada con la frase: "con la bendición de Dios"?

Este proyecto (el PSO) debe continuar, no solo en Puente Alto, tenemos que trabajarlo como una política pública a nivel nacional. Cuando Chile como Estado se equivocó en esta política habitacional, merece darse una segunda oportunidad. Por eso nosotros no vamos a parar hasta que Chile le responda a toda esa gente, y que Dios los bendiga. (Canal de Youtube, 2015). 
Probablemente, la microxenofobia descargada sobre los "tomadores" en la villa Coloane, tiene su origen en la estigmatización sobre los "no propietarios", y de esta forma, refuerza los ideales de la meritocracia y la cultura del esfuerzo, en donde la vivienda no es considerada un derecho universal, sino una mercancía. Incluso podemos ir más allá y considerar que el conjunto de estigmas de la villa y de las microxenofobias tienen como base una "ética del sufrimiento", pues se entiende que, en el sistema actual de subsidios, estas personas acceden a la propiedad en función de demostrar al conjunto social condiciones extremas de deterioro.

\section{Conclusiones}

Los hallazgos muestran que la percepción de Hidalgo, Urbina, Alvarado \& Paulsen (2017), de que la intervención en Bajos de Mena es señal de "un nuevo Estado neoliberal de bienestar, que corrige los errores del mercado inmobiliario" (p. 106), no es del todo correcta, porque las bases materiales, y sobre todo ideológicas del modelo mercantilista, están intactas. Ni siquiera en el caso de Francisco Coloane advertimos cambios en el discurso estatal, en tanto este ha sido cuidadosamente elaborado en el marco de una estrategia electoral que, por una parte, estigmatiza a la villa y a sus habitantes, y por otro, enaltece viejos valores que todavía sostienen la política chilena.

¿La estigmatización es entonces, parte de una "estrategia electoral"? Sí, pero no solamente. Es claro que el presidente Piñera activa esta táctica con objetivos político-electorales, con miras al triunfo de su plataforma y su eventual reelección. Recordemos que el Programa "Segunda Oportunidad" se inicia sin objetivos claros ni un diagnóstico mínimo, y en el último año de su primer mandato. Los discursos presidenciales, los del senador Ossandón, y los de otros políticos son diáfanos al impulsar una narrativa en la que el Gobierno de derecha "corrige" los errores de los gobiernos emanados de la Concertación, con miras a que el PSO se convierta en un programa "nacional".

Pero también, como señalamos, la estrategia de estigmatización trasciende lo puramente electoral y las luchas partidistas. Significa un acto de Estado, y en este sentido, cobra importancia la afirmación de Jiménez (2015), quien considera que la forma en que se implementó el PSO, vulnera la seguridad de la tenencia de los habitantes y representa una violación a los pactos internacionales de derechos humanos. Lo que no es seguro, es si los responsables de la administración pública -de uno u otro signo político-, son conscientes de la responsabilidad de Estado que tienen en sus manos, lo que resulta no solo "triste", -como menciona en entrevista un habitante reclamando al gobierno que recurra a esas tácticas-, sino que es incluso, criminal.

Hacia el final de su ensayo, Goffman (1970) se pregunta si más allá de la función social general, los estigmas tienen funciones particulares de acuerdo a su tipo. En el caso de los estigmas territoriales en la villa Francisco Coloane, de lo que se trata, especulamos, es de mantener la política de erradicación como una estrategia legítima de control mercantilista del suelo urbano. Vestida con los mejores ropajes de la caridad y el humanismo cristiano; con encomiables justificaciones y discursos de preocupación por la calidad de vida de los más pobres, la erradicación sigue siendo la forma en que el Estado neoliberal los desplaza hacia la periferia, generando mayor segregación en la ciudad. En este sentido, Sabatini et. al. (2013) tienen razón cuando argumentan que los estigmas territoriales funcionan como mecanismo de reproducción de las desigualdades sociales, al promover la gentrificación.

\section{Agradecimientos}

CONACYT, Consejo Nacional de Ciencia y Tecnología, Programa de Becas 2017. A las y los pobladores y dirigentas de la villa Francisco Coloane. A Claudia Bustos e Ignacio Moulian, del Ministerio de Vivienda y Urbanismo. A Francisco Sabatini, Daniela Machtig y Tai Lin.

\section{Dedicatoria}

Al entrañable compañero Cristian Pacheco (+), quien, entre otras inquietudes, colaboró con el proyecto Bajos de Mena TV y en la revista La Raza Cómica. Su ejemplo perdura en la juventud chilena organizada.

\section{Referencias}

Álvarez, M. J. (2017). The Weakness Of Symbolic Boundaries: Handling Exclusion Among Montevideo's Squatters. International Journal of Urban and Regional Research, 41(2), 251-265. https://doi.org/10.1111/1468-2427.12450

Barahona, M. \& Hinojosa, J. (2019). Entre derecho a la ciudad, segregación y estigma: dos estudios de caso al sur de Quito, Ecuador. Anuario de espacios 
urbanos, historia, cultura y diseño, 25. Recuperado de http://espaciosurbanos.azc.uam.mx/index.php/ principal/article/view/305

Bayón, M. C. (2012). El "lugar" de los pobres: espacio, representaciones sociales y estigmas en la ciudad de México. Revista mexicana de sociología, 74(1), 133-166. Recuperado de http://www.scielo.org. $\mathrm{mx} / \mathrm{scielo} . \mathrm{ph}$ ? $\mathrm{script}=\mathrm{sci}$ _arttext\&pid=S0188$25032012000100005 \&$ \&rm $=$ iso

Bologna, E., Morales, M. \& Plaza, V. (2017). El derecho a la ciudad en cuestión: segregación residencial y experiencias de circulación de jóvenes en la Ciudad de Córdoba, Argentina. Quid16, 7(11). Recuperado de https://ri.conicet.gov.ar/handle/11336/54837

Bourdieu, P. (1997). Razones prácticas. Sobre la teoría de la acción: Barcelona, España : Anagrama.

Boyack, A. J. (2017). Side by side: revitalizing urban cores and ensuring residential diversity. ChicagoKent Law Review, 92(2), 435. Recuperado de https:// ssrn.com/abstract $=2876423$

Brevis, H. R. \& Corvalán, A. L. (2019). Tracing routines: the role of the railway in daily practices and interurban mobilities of the inhabitants of La Araucanía, Chile. Urbe. Revista Brasileira de Gestão Urbana, 11. https://doi.org/10.1590/2175-3369.011.002.ao02

Carrillo, L., Pattillo, M., Hardy, E., \& Acevedo-Garcia, D. (2016). Housing Decisions Among Low-Income Hispanic Households in Chicago. Cityscape, 18(2), 109-150. Recuperado de http:/www.jstor.org/ stable/26328259

Carvajal, C. (25 de octubre de 2012). "Casas Copeva": Fisco deberá pagar $\$ 2,9$ millones a dueños después de 15 años. El Mercurio. Recuperado de https:// www.plataformaurbana.cl/archive/2012/10/25/casascopeva-fisco-debera-pagar-29-millones-a-duenosdespues-de-15-anos/

Céspedes , R. (2019). Territorios y personajes monstruosos de la Llajta: imaginarios sociales del peligro y la inseguridad ciudadana en el Cercado cochabambino. (Tesis de Maestría). Universidad Mayor de San Simón, Bolivia. Recuperado de http:// hdl.handle.net/123456789/13409
Cociña, C. (2016). Habitar Desigualdades: Políticas Urbanas y el despliegue de la vida en Bajos de Mena. Serie de Documentos de trabajo de PNUD, 5. Recuperado de https://www.researchgate.net/ publication/328048901 Habitar_desigualdades Politicas_urbanas_y_el_despliegue_de_la_vida_en_ Bajos_de_Mena

Cornejo, A. (2015). Imaginarios urbanos y segregación socioespacial. Un estudio de caso sobre Quito. Cuadernos de vivienda y urbanismo, 8(16), 246-263. https://doi.org/10.11144/javeriana.cvu8-16.iuss

Cruz, F. \& Isunza, G. (2017). Construcción del hábitat en la periferia de la Ciudad de México: Estudio de caso en Zumpango. EURE, 43(129), 187-207. https:// doi.org/10.4067/s0250-71612017000200009

Da Cunha, T.-A., Rezende-Alves, B. \& HenriquesRibeiro, C. (2020). A la sombra de la periferización Posibles diálogos entre el Programa de Viviendas "Minha Casa Minha Vida" y dinámica migratoria: El caso de la Región Metropolitana de Belo Horizonte y sus microrregiones limítrofes. Revista EURERevista de Estudios Urbano Regionales, 47(140). Recuperado de http://eure.cl/index.php/eure/article/ view/3495/1332

Elorza, A. L. (2019). Segregación residencial y estigmatización territorial. Representaciones y prácticas de los habitantes de territorios segregados. Revista EURE-Revista de Estudios Urbano Regionales, 45(135). https://doi.org/10.4067/s025071612019000200091

Gajardo Martínez, P. N. (2013). Bajos de Mena 2054: Centro Urbano para la zona sur de Santiago (Tesis de Pregrado). Universidad de Chile, Chile. Recuperado de http://repositorio.uchile.cl/handle/2250/117002

Goffman, E. (1970). Estigma : la identidad deteriorada: Buenos Aires, Argentina : Amorrortu.

Gómez, J. \& Herrera, B. (2016). La ciudad fragmentada: la construcción de identidad barrial en condiciones de segregación socio espacial: el caso de la población Entre Ríos de la comuna de Hualqui (Tesis de Pregrado). Universidad del BioBio, Recuperado de http://repobib.ubiobio.cl/jspui/ handle/123456789/1826 
González, M. (2012). Lo mejor de CIPER 2. El periodismo que remece a Chile. Chile: Editorial Catalonia.

Hidalgo, R., Urbina, P., Alvarado, V. \& Paulsen, A. (2017). Desplazados y ¿olvidados?: contradicciones respecto de la satisfacción residencial en Bajos de Mena, Puente Alto, Santiago de Chile. Revista INVI, 32(89), 85-110. https://doi.org/10.4067/s071883582017000100085

Hwang, J. (2016). The social construction of a gentrifying neighborhood: Reifying and redefining identity and boundaries in inequality. Urban Affairs Review, 52(1), 98-128. https://doi.org/10.1177/1078087415570643

Iglesias, R. (2014). El papel de las concepciones espaciales subjetivas en la segregación residencial de los barrios con alta densidad de inmigración : el caso de la ciudad de Sevilla (Tesis de Doctorado). Universidad Pablo de Olavide, Sevilla, España. Recuperado de https://dialnet.unirioja.es/servlet/ tesis ? codigo $=89289 \&$ orden $=1 \&$ info $=$ link

Jarness, V.(2017). Cultural vs economic capital: Symbolic boundaries within the middle class. Sociology, 51(2), 357-373. https://doi.org/10.1177/0038038515596909

Jiménez, F. (2015). Villa Francisco Coloane: vulneración del derecho a la tenencia. En A. Rodríguez, P. Rodríguez \& A. Sugranyes (Eds.), Con subsidio, sin derecho (pp. 77-93). Santiago: Ediciones SUR.

Jiménez, P. (2017). Rehabilitación en barrios segregados: Análisis de la movilidad habitacional en Bajos de Mena (Tesis de Magíster). Pontificia Universidad Católica de Chile, Santiago, Chile. Recuperado de https://estudiosurbanos.uc.cl/ exalumnos/rehabilitacion-en-barrios-segregadosanalisis-de-la-movilidad-habitacional-en-bajos-demena/

Kataure, V. \& Walton-Roberts, M. (2015). The Good, the Bad, and the Suburban Tracing North American Theoretical Debates about Ethnic Enclaves, Ethnic Suburbs, and Housing Preference. En C. Teixeira \& W. E. I. Li (Eds.), The Housing and Economic Experiences of Immigrants in U.S. and Canadian Cities (pp. 146-175). Toronto: University of Toronto Press.
Klein, C. (Producer). (2013). Discurso de Caterina Klein, Gobernadora de la Provincia de Cordillera [Archivo de video]. Recuperado de https://m.youtube.com/ watch? $\mathrm{v}=\mathrm{AFfb} 7 \mathrm{ccRddU}$

Krysan, M. \& Crowder, K. (2017). Cycle of segregation: Social processes and residential stratification. Russell Sage Foundation.

Krysan, M. \& Farley, R. (2002). The residential preferences of blacks: Do they explain persistent segregation? Social Forces, 80(3), 937-980. https:// doi.org/10.1353/sof.2002.0011

Lefebvre, H. (2013). La producción del espacio. Madrid: Capitán Swing.

Maffet, H. A., Molina, R. \& Palma, F. (1948). Puente Alto: 1898- 8 de Enero - 1948 : Publicación oficial de la I. Municipalidad con motivo del cincuentenario de la Comuna.

Massey, D. \& Denton, N. (1988). The Dimensions of Residential Segregation. Social Forces, 67(2), 281315. https://doi.org/10.1093/sf/67.2.281

Massey, D. \& Denton, N. (1993). American apartheid: Segregation and the making of the underclass. Harvard: Harvard University Press.

Maureira, M. (2011). Cementerio católico de Puente Alto Ex Bajos de Mena. [Reporte de investigación]. Muerte en Chile.

Mier y Terán, A., Vázquez, I. \& Ziccardi, A. (2012). Pobreza urbana, segregación residencial y mejoramiento del espacio público en la Ciudad de México. Sociologias, 14(30), 118-155. https://doi. org/10.1590/S1517-45222012000200005

MINVU, M. d. V. y. U.. (2012). Balance de Gestión Integral año 2012. Chile. Recuperado de http:// minvuhistorico.minvu.cl/incjs/download. aspx?glb_cod_nodo=20061113164732\&hdd_nom_ archivo=BGI-2012-Subsecretaria-de-Vivienda-yUrbanismo.pdf

MINVU, M. d. V. y. U. (Producer). (2013). Traslado de pobladores de Bajos de Mena [Archivo de video]. Recuperado de https://youtu.be/wY3Bm3fowhM 
MINVU, M. d. V. y. U. (2016). Informe final de evaluación del Programa Mejoramiento de Condominios Sociales y Programa de Regeneración de Condominios Sociales (Exprograma de Recuperación de Condominios Sociales Segunda Oportunidad). Chile. Recuperado de https://www. dipres.gob.cl/597/articles-149531_informe_final.pdf

Miranda, N. (2017). El Capital y su repercusión en la Geografia Urbana (El caso de la CMPC en Puente Alto 1970-1973) (Tesis de Pregrado). Universidad de Chile, Santiago, Chile. Recuperado de http:// repositorio.uchile.cl/bitstream/handle/2250/146917/ El-capital-y-su-repercusion-en-la-geografia-urbana. pdf? sequence $=1$

Moctezuma, V. (2017). Experiencia y significados simbólicos de los habitantes de conjuntos urbanos de interés social en México: segregación, diferencia y distinción. Estudios Demográficos y Urbanos, 32(3), 487-514. https://doi.org/10.24201/edu.v32i3.1723

Mora, P., Sabatini, F., Fulgueiras, M. \& Innocenti, D. (2014). Disyuntivas en la política habitacional chilena. Notas Públicas, 3. Recuperado de https:// politicaspublicas.uc.cl/wp-content/uploads/2015/02/ estudio.pdf

Moreno, C. (2016). Segregation in the urban space of Soacha. Transmilenio as an integrating tool? Revista de Arquitectura, 18(1), 48-55. https://doi. org/10.14718/RevArq.2016.18.1.5

Moreno, L. (2015). Entre la inseguridad y seguridad urbana: visiones del habitar, espacio social y los imaginarios en Ciudada Juárez. En Adrián Aguilar, Segregación urbana y espacios de exclusión (pp. 257-283). D.F.: Porrúa.

Naranjo, J. M. (2018). Espacios de uso público: una nueva realidad sociogeogáfica de marginalidad territorial en la periferia barrial. Contextos: Estudios de Humanidades y Ciencias Sociales, 40. Recuperado de http://revistas.umce.cl/index.php/contextos/ article/view/1385

Nieuwenhuis, J., Tammaru, T., van Ham, M., Hedman, L. \& Manley, D. (2019). Does segregation reduce socio-spatial mobility? Evidence from four European countries with different inequality and segregation contexts. Urban Studies, 57(1). https://doi. org/10.1177/0042098018807628
Oldrup, H. (2015). Differential belongings: sociocultural distinctions in suburban residential areas. Journal of Housing and the Built Environment, 30(3), 383-401. https://doi.org/10.1007/s10901-014-9418-1

Ossandón, M. (Producer). (2015). Segunda Oportunidad [Archivo de video]. Recuperado de https://m.youtube. com/watch? $\mathrm{v}=\mathrm{ONJ}$-tvlX5Wk

Pansza, E. M., Gutiérrez, O. \& Ortíz, R. (2017). Estrategia social y urbana para la recuperación del espacio público de un barrio emblemático: experiencias de la colonia chaveña de Ciudad Juárez, Chihuahua. Vivienda y Comunidades Sustentables, 1, 45-58. https://doi.org/10.32870/rves.v0i1.4

Pizarro, C. (8 de julio de 2013). Bajos de Mena: sobreviviendo en el gueto más grande de Chile. The Clinic. Recuperado de https://www.theclinic. cl/2013/07/08/bajos-de-mena-sobreviviendo-en-elgueto-mas-grande-de-chile-2/

Roberti, E. (2013). El barrio como delimitación de fonteras socioespaciales en áreas con pobreza estructural. El caso del barrio El aluvión. Paper presented at the VII Jornadas de Jóvenes Investigadores. Instituto de Investigaciones Gino Germani, Buenos Aires, Argentina.

Rokem, J. \& Vaughan, L. (2018). Segregation, mobility and encounters in Jerusalem: The role of public transport infrastructure in connecting the 'divided city’. Urban Studies, 55(15), 3454-3473. https://doi. org/10.1177/0042098017691465

Ruiz, J. (2016). La persistencia de la segregación y la desigualdad en barrios socialmente diversos: un estudio de caso en La Florida, Santiago. EURE, 42(125), 81-108. Recuperado de http://repositorio. uchile.cl/handle/2250/138560

Sabatini, F. (2015). Transformación de la periferia urbana popular: entre el estigma y la devolución espacial. En A. Lindón \& C. Mendoza (Eds.), La periferia metropolitana: entre la ciudad prometida y un lugar para habitar la Ciudad de México (pp. 5791).

Sabatini, F. \& Rasse, A. (2017). Segregación espacial de hogares indígenas en ciudades chilenas. Andamios, 14(35), 309-333. https://doi.org/10.29092/uacm. v14i35.581 
Sabatini, F., Rasse, A., Cáceres, G., Robles, M. S., \& Trebilcock, M. P. (2017). Promotores inmobiliarios, gentrificación y segregación residencial en Santiago de Chile. Revista mexicana de sociología, 79(2), 229260. Recuperado de http://www.scielo.org.mx/scielo. php?pid=S0188-25032017000200229\&script $=$ sci abstract

Sabatini, F., Salcedo, R., Gómez, J., Silva, R. \& Trebilcock, M. (2013). Microgeografías de la segregación: estigma, xenofobia y adolescencia urbana. En F. Sabatini, G. Wormald \& A. Rasse (Eds.), Segregación de la vivienda social: ocho conjuntos en Santiago, Concepción y Talca (pp. 33-66). Santiago: Universidad Católica de Chile.

Saieg, D. \& Valadez, L. (2013). Cohesión social y otredad en el barrio República, Santiago centro. En F. Sabatini, G. Wormald, A. Rasse, \& M. Trebilcock (Eds.), Cultura de cohesión e integración social en Ciudades chilenas (pp. 65-87). Santiago: Universidad Católica de Chile.

Salazar, G. (1985). Labradores, peones y proletarios. Santiago: LOM ediciones.

Salazar, G. (2003). Historia de la acumulación capitalista en Chile. Santiago: Lom ediciones.

Salgado, M., Cáceres, S., Gurría, L., Gancedo, N., Basuino, M., Solari, C., . . . Re, J. (2017). Estudio del uso y apropiación de espacios colectivos de la vivienda social en un área de reciente urbanización: Parque Habitacional Ibarlucea. Paper presented at the FAPyD - 2016 - VIII Jornadas Arquitectura Investiga. Recuperado de http://hdl.handle.net/2133/6857

Santillán, A. M. (2017). El sentir frente a la estigmatización territorial. Travesías de topofilia en el Sur de Quito. Revista INVI, 32(91), 189-210. http:// dx.doi.org/10.4067/S0718-83582017000300189

Segura, R. (2012). Elementos para un crítica de la noción de segregación residencial socio-económica: desigualdades, desplazamientos e interacciones en la periferia de La Plata. Quid 16: Revista del Área de Estudios Urbanos, 2, 106-132. Recuperado de https:// publicaciones.sociales.uba.ar/index.php/quid16/ article/view/1118

Skobba, K. \& Goetz, E. G. (2013). Mobility Decisions of Very Low-Income Households. Cityscape, 15(2),
155-171. Recuperado de https://www.huduser.gov/ portal/periodicals/cityscpe/vol15num2/ch11.pdf

Stevenson, C., Easterbrook, M., Harkin, L., McNamara, N., Kellezi, B. \& Shuttleworth, I. (2018). Neighborhood Identity Helps Residents Cope with Residential Diversification: Contact in Increasingly Mixed Neighborhoods of Northern Ireland. Political Psychology, 40(2), 277-295. https://doi.org/10.1111/ pops. 12510

Stevenson, C., McNamara, N., Kellezi, B., Easterbrook, M., Shuttleworth, I. \& Hyden, D. y. (2018). Reidentifying residential mixing: Emergent identity dynamics between incomers and existing residents in a mixed neighbourhood in Northern Ireland. European Journal of Social Psycholog, 49(2), 413428. https://doi.org/10.1002/ejsp.2529

Teixeira, C. (2015). Introduction to Part One The Housing Experiences of Immigrants. En C. Teixeira \& W. E. I. Li (Eds.), The Housing and Economic Experiences of Immigrants in U.S. and Canadian Cities (pp. 23-42). Toronto: University of Toronto Press.

Theodos, B., Coulton, C. J. \& Pitingolo, R. (2015). Housing unit turnover and the socioeconomic mix of low-income neighborhoods. The ANNALS of the American Academy of Political Social Science Quarterly, 660(1), 117-135. https://doi. org/10.1177/0002716215576112

Tilly, C. (2000). La desigualdad persistente. Buenos Aires: Ediciones Manantial.

Toft, M. (2018). Enduring contexts: Segregation by affluence throughout the life course. The Sociological Review, 66(3), 645-664. https://doi. org/10.1177/0038026117741051

Valenzuela, D. (2010). Historia Social de Puente Alto (Tesis de Pregrado). Universidad de Santiago de Chile, Santiago, Chile. Recuperado de https:// docplayer.es/33007088-Universidad-de-santiago-dechile-facultad-de-humanidades-departamento-dehistoria.html

Varela, J. S. \& Suárez, M. J. (2014). Calidad de vida y urbanismo en la vivienda social: el caso de Villa El Volcán. Santiago: Universidad Academia de Humanismo Cristiano. Recuperado de http://bibliotecadigital. academia.cl/handle/123456789/3178 
Vázquez, J. J., Suarez, A. \& Berríos, A. (2018). Stigma, extreme poverty and residential situation: Residential segregation, household conditions and social relationship satisfaction among trash pickers in León, Nicaragua. International Social Work, 63(3). https:// doi.org/10.1177/0020872818788122

Villalobos, M. \& Núñez, A. (2018). "Mi vivienda y mi familia". La elección residencial como reproducción de la violencia simbólica en el municipio de Nezahualcóyotl. Quid 16: Revista del Área de Estudios Urbanos, 10, 156-181. Recuperado de https://dialnet. unirioja.es/servlet/articulo? codigo $=6702386$

Villazor, R. C. (2017). Residential Segregation and Interracial Marriages. Fordham L. Rev., 86, 2717. Recuperado de https://ir.lawnet.fordham.edu/ftr/ vol86/iss6/7/
Zapata, I., Galleguillos, X. \& Wehrhahn, R. (2-4 de junio de 2009). Espacio e imagen en la gestión de transformación urbana: Barrio Bajos de Mena, Santiago de Chile. Paper presented at the 5th International Conference Virtual City and Territory, Barcelona, España.

Zomosa, G. (2016). Remodelación urbano habitacional del conjunto Francisco Coloane, Bajos de Mena: desde la célula urbana a la habitacional (Tesis de Pregrado). Universidad de Chile, Santiago, Chile. Recuperado de http://repositorio.uchile.cl/ handle/2250/143470 